\title{
Orientação quanto à queixa escolar relativa a adolescentes: especificidades
}

\author{
Cárita Portilho de Lima \\ Universidade Federal de Uberlândia - MG \\ Marina Borges e Silva Prado \\ Universidade Federal de Uberlândia - MG \\ Beatriz de Paula Souza \\ Universidade Estadual de São Paulo - SP
}

\begin{abstract}
Resumo
Este artigo visa apresentar e discutir especificidades do atendimento em "Orientação à Queixa Escolar" (OQE) com adolescentes, desenvolvendose reflexões teórico-práticas frutos de experiências de intervenção em contexto clínico. Para tanto, expõe-se a concepção de adolescência nas quais se baseiam e analisa-se o ambiente escolar das escolas públicas, refletindo-se sobre políticas públicas de educação que atingem esse público e sobre o funcionamento de escolas que causam dificuldades nos processos de escolarização. A partir disso, são apresentas especificidades do atendimento em OQE a adolescentes: o estigma da incompetência escolar, o lugar da fala e de outras linguagens, a autoria do adolescente no processo de atendimento, o lugar do projeto de vida e especificidades da intervenção na escola. Por fim, destaca-se que o tema das dificuldades escolares enfrentadas por adolescentes merece aprofundamento por meio de estudos e pesquisas em Psicologia Escolar e Educacional, com vistas a desvelar meandros e vicissitudes dessa trama e a refinar propostas de intervenção na mesma.
\end{abstract}

Palavras-chave: Orientação à queixa escolar, adolescência, contexto clínico.

\section{Guidance on school complaint with adolescents: some specificities}

\begin{abstract}
In this work present and discuss the specificities of the psychological care in "Psychological Guidance to School Complaints" (OQE) with adolescents, proposing theoretical and practical reflections resulted of intervention experiences in clinical practice. For this purpose we expose a conception of adolescence in which it is based and analyze the public schools' environment. We ponder on public policies of education for this population and the functioning of the school system that may be leading to difficulties in the education process. Further we present the specificities of the psychological care in OQE with adolescents: the educational incompetence stigma, the speech's and other language's role, the adolescent's authorship in the care process, life project's role, and specificities of an intervention in the school. Finally, we emphasize that this theme of educational difficulties faced by adolescents deserves further serious study and research in Educational and School Psychology. This may help to uncover the vicissitudes of this area and to improve the intervention proposals to that.
\end{abstract}

Keywords: Psychological Guidance to School Complaints, adolescence, clinical context.

\section{Orientación a la queja escolar con adolescentes: especificidades}

\section{Resumen}

Este artículo tiene el objetivo presentar y discutir especificidades del atendimiento en "Orientación a la Queja Escolar" (OQE) con adolescentes, elaborando reflexiones teórico-prácticas fruto de experiencias de intervención en contexto clínico. Para ello se expone la concepción de adolescencia en la que se basa y se analiza el ambiente escolar de las escuelas públicas, reflexionando sobre políticas públicas de educación que inciden en ese público y sobre funcionamientos escolares que producen dificultades en los procesos de escolarización. A partir de esto se presentan especificidades del atendimiento en OQE a adolescentes: el estigma de la incompetencia escolar, el lugar del habla y de otros lenguajes, la autoría del adolescente durante el proceso de atendimiento, el lugar del proyecto de vida y las especificidades de la intervención en la escuela. Por último, se hace hincapié en que el tema de las dificultades escolares enfrentadas por adolescentes merece profundizarse por medio de estudios e investigaciones en Psicología Escolar y Educacional, con la intención de descubrir desvíos y vicisitudes de esa trama y a perfeccionar propuestas de intervención.

Palabras Clave: Orientación a la Queja Escolar, adolescência, contexto clínico. 


\section{Introdução}

Muitos responsáveis por adolescentes vêm buscando atendimento em serviços-escola de Psicologia e demais serviços públicos que atuam em casos de queixa escolar. Diante dessa demanda, a Psicologia, em sua interface com os conhecimentos e contextos da área escolar e da clínica, enfrenta o desafio de pensar sobre o atendimento de adolescentes que estão excluídos na escola.

Este trabalho pretende discutir saberes construídos a partir de atendimentos psicológicos a jovens que passam por dificuldades em sua vida escolar, realizados no serviço "Orientação à Queixa Escolar" do Instituto de Psicologia da Universidade de São Paulo. O objetivo dessa reflexão é dar visibilidade a especificidades desse trabalho e contribuir para a consolidação de discussões teórico-práticas sobre a intervenção junto a processos de escolarização em contextos clínicos.

Para refletir sobre o atendimento a adolescentes que passam por dificuldades em seu processo escolar, primeiramente explicitamos a concepção de adolescência que embasa nossa atuação e em seguida expomos e discutimos características e funcionamentos do ambiente escolar desses adolescentes, centrando-nos do Ensino Fundamental II - nome paulistano atual para o antigo Ginásio o qual varia conforme a rede escolar. Elegemos alguns aspectos da vida nas escolas que percebemos serem de extrema relevância na produção, manutenção e aprofundamento de queixas escolares.

Passaremos, então, a tratar dos temas predominantes e de algumas técnicas mais específicas no atendimento de jovens, fechando o texto em seguida com algumas considerações gerais sobre esse atendimento.

\section{Concepção de adolescência}

Pautamos nosso trabalho pela concepção de adolescência como foi historicamente construída no bojo de relações sociais. Neste sentido, alinhamo-nos aos trabalhos realizados pelo grupo de pesquisadores da perspectiva sócio-histórica da Pontifícia Universidade Católica de São Paulo - PUCSP, constituído por autores como Sérgio Ozella, Ana Mercês Bahia Bock e Wanda Maria Junqueira Aguiar, que defendem a necessidade de se entender a inserção do jovem a partir de uma perspectiva histórica que considere suas condições objetivas de vida.

Ozella (2002) chama a atenção para o fato de que a concepção vigente na Psicologia sobre adolescência está fortemente ligada a estereótipos e estigmas que identificam essa fase do desenvolvimento como uma etapa marcada por tormentos e conturbações, concepção fortemente endossada por algumas abordagens psicanalíticas e por Erik Erikson, entre outros autores; mas na perspectiva de Bock (2004),

A adolescência é vista como uma construção social que tem suas repercussões na subjetividade e no desenvolvimento do homem moderno e não como um período natural do desenvolvimento. É um momento significado, interpretado e construído pelos homens. Estão associadas a ela marcas do desenvolvimento do corpo. Essas marcas constituem também a adolescência como fenômeno social, mas o fato de existirem como marcas do corpo não deve fazer da adolescência um fato natural (p. 39).

Argumentam os autores que as modificações das relações de trabalho na sociedade moderna têm um papel de grande relevância na construção desse fenômeno. A sofisticação tecnológica do trabalho nessa sociedade passou a exigir uma formação técnica maior. Em decorrência dessa exigência, começou a reunir os jovens em um mesmo espaço - a escola - e os afastou do trabalho por um tempo. Somado a isso, o desemprego estrutural que constitui a sociedade capitalista começou a exigir que se retardasse tanto quanto possível o ingresso do jovem no mercado de trabalho (Clímaco, conforme citado por Aguiar, Bock, \& Ozella, 2002).

Nesse contexto, estabeleceram-se as condições para que os filhos fossem mantidos durante mais tempo sob a tutela de seus pais. Assim, a sociedade assiste à constituição de um novo grupo social: a adolescência. Tais questões históricas e sociais conferiram a este período da vida um caráter de latência - em que há um afastamento do trabalho e um preparo para a vida adulta; ou seja, os jovens já possuíam a força e as capacidades para ingressar no mundo adulto (como faziam até então), mas as necessidades sociais não mais os autorizavam a fazê-lo. Constitui-se a contradição básica da adolescência: os jovens apresentam todas as possibilidades cognitivas, afetivas e físicas para inserir-se na sociedade adulta, mas são impedidos de realizar essa inserção.

Em decorrência dessa configuração, começam a ser forjadas características que são comumente associadas à adolescência: a rebeldia, a moratória, a instabilidade, a vivência de conflitos, a onipotência, crises geracionais, a construção da identidade.

Nas camadas sociais menos favorecidas, às quais pertence a grande maioria daqueles que demandam os serviços de Orientação à Queixa Escolar - OQE, a ocorrência de jovens que vivem o período de moratória de maneira mais branda, ou até que não o vivem, é mais comum do que nas camadas mais abastadas. De modo geral, inserem-se no mercado de trabalho de maneira mais precoce e/ou assumem desde a infância responsabilidades pelos cuidados com a casa e os outros filhos de seus pais com mais frequência do que entre os adolescentes das elites. Assim, é preciso que o psicólogo se liberte do pensamento generalizante e atente para as características de vida e cultura dos grupos sociais de pertença do adolescente que atende, pois, como nos demais períodos da vida, tenderá a desenvolver-se constituído por estas características.

Concordamos com Barros (2002) que os adolescentes não constituem um grupo homogêneo, pois diferentes vivências e culturas impõem necessidades e formas particulares de experimentar a adolescência. Tal compreensão endossa a importância de entrarmos em contato com as singularidades dos adolescentes com os quais estamos trabalhando. 


\section{O ambiente escolar dos adolescentes}

A segunda questão que se coloca em nosso trabalho são características e funcionamentos do ambiente escolar dos adolescentes, que percebemos ter, na maioria das vezes, papel fundamental na produção de suas dificuldades de escolarização.

Nossa clientela adolescente, provavelmente representativa da que outros serviços gratuitos de atendimento psicológico recebem com queixas escolares, é constituída majoritariamente por estudantes do Ensino Fundamental II. Assim, é a estes anos escolares que iremos nos referir a seguir.

\section{Políticas públicas em Educação e a produção de dificuldades de escrita}

Deparamo-nos com o fenômeno em que é produzida uma quantidade cada vez mais alarmante de adolescentes que prosseguem sua trajetória escolar sem saber ler e escrever. Para entendermos esse cenário e como se constituiu, é indispensável considerarmos as políticas públicas de Educação implantadas nos últimos anos no Brasil a fim de enfrentar o grande índice de repetência nas séries iniciais do Ensino Fundamental, diminuir a defasagem série/idade e combater a evasão escolar.

Entre as políticas públicas educacionais de maior impacto encontra-se a Progressão Continuada. Tal política foi concretizada por meio de um decreto-lei que propôs uma reorganização do Ensino Fundamental em dois ciclos: ciclo I - do $1^{\circ}$ ao $5^{\circ}$ ano; e ciclo II do $6^{\circ}$ ao $9^{\circ}$ ano. No decorrer de cada um deles, não é possível a retenção dos alunos a não ser por número excessivo de faltas. Sua implantação deu-se em diversos estados e municípios brasileiros, começando por São Paulo, onde estuda a imensa maioria daqueles que atendemos. Há uma parcela deles que está na rede particular, mas não encontramos entre estes nenhum afetado por esta política, a não ser alguns que migraram de uma rede a outra.

Segundo Viégas (2007), a implantação da Progressão Continuada por parte do poder público respalda-se no entendimento que a reprovação, um efeito da precariedade do sistema público brasileiro, é um grande ônus financeiro. A discussão cada vez mais efervescente entre os gestores educacionais sobre tal aspecto da reprovação tem como resultado a implementação da Progressão Continuada em 1998, no Estado de São Paulo.

O objetivo declarado dessa política seria o de solucionar o problema da exclusão dos alunos que frequentam a escola - a exclusão na escola; no entanto, estudos como o de Viégas (2007) revelaram que, na prática, foi mantida a lógica do sistema seriado. A Progressão Continuada tornou-se mera promoção automática dos estudantes em um sistema seriado de ensino, independentemente de sua apropriação ou não dos conhecimentos básicos previstos pelo currículo.

A forma de implantação de tal política prescindiu da participação dos professores e de um preparo das escolas para essa mudança, fato que criou importantes condições para que uma mudança real do sistema seriado para o de ciclos fracassasse.

É nesse contexto que as queixas sobre adolescentes relacionadas a dificuldades de aprendizagem e/ou de comportamento destes no ambiente escolar têm se constituído como uma significativa demanda e desafio para os psicólogos. Temos encontrado muitos adolescentes que frequentam as séries finais do Ensino Fundamental sem saber ler e escrever, apenas fazem cópias. Encontramos também alunos que, mesmo sabendo ler e escrever, não conseguem apropriar-se dos demais conteúdos escolares.

Assim, ao nos depararmos com uma demanda significativa de adolescentes com queixas escolares, não podemos nos furtar à discussão a respeito das ações políticas que têm contribuído para a construção desse fenômeno.

\section{A indisciplina e a violência na escola}

Os personagens principais da trama que engendra e mantém as queixas escolares (geralmente professores, responsáveis e os adolescentes em atendimento) nos desenham um quadro de classes conturbadas, por vezes assemelhadas a campos de guerra em que se digladiam estudantes e professores. Encontramos tal desenho também na literatura e relatos daqueles que trabalham e estudam o ambiente escolar contemporâneo no Brasil ${ }^{1}$. Bullying é uma palavra que se tornou comum para nomear diversos tipos de humilhação e assédio que ocorrem com frequência preocupante.

Descrevem-se cenas em que é comum entre os alunos o desinteresse, a falta de atenção às aulas e o não cumprimento das tarefas escolares.

Ter clareza sobre a existência desse cenário é essencial para que o psicólogo possa fazer um trabalho que não individualize a relação do adolescente com sua escola nem atente para o caráter coletivo e institucional de embates nessa relação.

A produção dessas condições escolares é um tema extenso, de que faz parte a presença de jovens em etapas muito defasadas de alfabetização, muitos dos quais poderiam ser considerados analfabetos estando já no $2^{\circ}$ ciclo do Ensino Fundamental ou mesmo mais adiante, como anteriormente mencionado. Temos observado alguns modos mais frequentes de lidar com essa situação injusta e humilhante destes jovens, geradora de sofrimento e tensão. Vem-nos à mente o subtítulo da obra magistral de Maria Helena Souza Patto "A Produção do Fracasso Escolar: histórias de submissão e rebeldia" (2008). Ressaltamos que tipos "puros" são muito raros; falemos em predominâncias e complexidade.

\section{Submissão}

Alguns se esforçam por disfarçar sua condição, escondendo-se por trás de cópias sem sentido e estratégias de observação diversificadas e inteligentes, para preencher 1 Vide, por exemplo, Freller (2001) e Ruotti, Alves e Cubas (2006). 
espaços de respostas que não podem ser resolvidas autenticamente, pois os alunos nem mesmo podem compreender as perguntas escritas. À custa de grande esforço, com investimento psíquico considerável, até conseguem que seus cadernos se pareçam com os de um aluno devidamente alfabetizado para o ano escolar, ou pouco atrasado. Alia-se principalmente a esse procedimento uma bem-sucedida invisibilidade de comportamento em classe: é comum esses alunos atingirem o objetivo de ocultar seu não saber. Quando esse ocultamento falha, são chamados de copistas.

Este comportamento também é encontrado nos anos escolares anteriores, mas nos adolescentes, até porque está instalado há mais tempo, costuma estar mais enrijecido. No extremo, não tão incomum, a esperança de aprender a ler e a escrever esvai-se, espraiando-se na descrença em sua capacidade geral de aprender. A introjeção da ideia de "burrice" embota o pensamento e defasagens reais instalam-se perigosamente, assim como a ojeriza ao mundo das letras, outrora ansiosamente desejado.

\section{Rebeldia}

Caminhos distintos surgem nessa vertente. Alguns, tensos e revoltados, tornam-se explosivos, agredindo verbal e/ou fisicamente colegas e professores. Tais agressões são frequentemente motivadas por chacotas, ofensas, cobranças e apelidos jocosos. Se há casos em que se protegem por medo, em muitos o efeito é o contrário, intensificando-se seu lugar de exclusão e tornando-se eles alvo de crueldade pela exposição de sua condição e por sua sensibilidade. Este último caso, um círculo vicioso, vem sendo chamado de bullying.

Outros enveredam pela senda das agressões por uma via que tem presentes também outros elementos. Desonrados e inferiorizados por não saberem ler e escrever a contento, procuram "salvar" sua dignidade e o respeito de seus colegas e de adultos da escola assumindo o papel de valentões e pessoas perigosas. Por vezes há blefe, mas infelizmente nem sempre. A desesperança torna-os vulneráveis ao mundo dos conflitos com a lei. O fato de a escola muitas vezes apelar para órgãos do aparato judicial, como o Conselho Tutelar e mesmo a polícia, pedindo ajuda e providências, intensifica essa vulnerabilidade. É o que se chama judicialização da Educação.

\section{Outros modos de funcionamento escolar produtores de um ambiente conturbado}

Como o tema é extenso demais para o escopo deste escrito, citamos apenas mais dois outros elementos da vida escolar que se encontram, na maioria das vezes, naturalizados.

Os professores, em busca de um ganho que lhes dê condições dignas de vida, não raro sobrecarregam-se de um número excessivo de aulas. Assim suas aulas têm pouca qualidade, improvisadas, inadequadas às necessidades pedagógicas e características dos alunos e eles mantêm uma relação distanciada com estes - até porque não poderia ser diferente, dado seu número elevado.

O $6^{\circ}$ ano $/ 5^{a}$ série, o primeiro ano do Ensino Fundamental II (antigo ginasial), é um ano de passagem para um arranjo da vida escolar com diferenças marcantes: de um ou dois passam a ter muitos professores, disciplinas novas, necessidade de nova organização de cadernos, exigência de maior autonomia, etc. Além disso, os alunos tendem a ver-se passando à adolescência (mesmo com 10 anos), disparando muitas novidades no modo de comportar-se, apresentar-se e relacionar-se, inclusive com autoridades. Experiências (Leite, 1993; Mendes, Kuroda, \& Facci, 2008) têm mostrado que, nas raras vezes em que as escolas tematizam e investem em preparar e lidar com essa passagem, desde o ano anterior, há muitos ganhos em termos de produzir-se um ambiente mais propício à aprendizagem e à saúde mental de alunos e professores do início do Ensino Fundamental II, mas isso é raro.

\section{Orientação à queixa escolar com adolescentes}

Entendemos a queixa escolar como um fenômeno entretecido nas tramas institucionais e relacionais vivenciadas nas escolas e na sociedade. Tal concepção direciona nossa intervenção junto aos que passam por dificuldades de escolarização, a outros participantes significativos da produção e manutenção de tais queixas (geralmente pais e a escola) e nas relações entre essas pessoas.

Entendemos que processos interventivos que visem colaborar para uma superação das queixas escolares que não seja meramente adaptativa (portanto, conservadora) devem abarcar o maior número possível de pessoas que fazem parte significativa da trama que produz e mantém ou aprofunda as dificuldades e sofrimentos apresentados, com vistas a problematizar e ressignificar o processo de escolarização, a saber, as pessoas pertencentes aos contextos escolar, familiar e social do adolescente em questão.

É parte do trabalho do psicólogo que atua com as queixas escolares buscar mobilizar agentes que possam imprimir movimento e desenvolvimento onde há paralisia e propiciar mudanças positivas na história escolar do adolescente que vão além da promoção de seu ajuste alienado a ambientes adoecidos; contudo, nossa experiência tem-nos mostrado que existem peculiaridades quando intervimos junto a adolescentes que comparecem à OQE. Passamos a discutir essas peculiaridades.

\section{O estigma da incompetência escolar}

No início dos atendimentos é comum ser difícil a abordagem dos assuntos escolares com os adolescentes. São diversas as estratégias que os psicólogos utilizam para esquivar-se desse tema. Uma delas, especialmente eficiente com psicólogos que têm como pressuposto que dificuldades escolares são sintomas de problemas familiares, é falar desses problemas. Sem dúvida, a vida em família é uma esfera 
de experiência importante de ser considerada na emergência de uma queixa escolar, mas o psicólogo incauto poderá ter dificuldades em perceber, quando tratar de família, se está usando um estratagema para escapar ao tema da vida escolar e tenderá a intensificar o uso desse artifício evitativo. Intensificará também sua compreensão - equivocada, a nosso ver - de que dificuldades escolares costumam ser sintomas de problemas da dinâmica familiar. Alguns adolescentes usam para esse mesmo fim outros assuntos que não a família, como namoros e amigos. Outros tentam disfarçar ou negar as dificuldades que enfrentam no contexto escolar. Dizem que os conflitos acontecem apenas como forma de reagir a provocações externas, falam que estão se saindo bem em disciplinas em que encontram dificuldades, fingem escrever usando palavras cuja escrita decoraram ou copiam quando não sabem escrever.

Em alguns casos há uma recusa explícita a falar sobre a escola. Essas dificuldades na abordagem inicial das questões escolares têm nos levado a refletir sobre seus significados.

Quando comparecem a um atendimento psicológico por causa de dificuldades escolares, os adolescentes quase sempre trazem consigo uma história de muitos anos de processo de escolarização: a maioria já frequenta a escola há mais de cinco anos. Estão há muito tempo acostumados a viver histórias de insucesso e sofrimento em suas atividades escolares. Em geral, trazem profundas marcas do estigma da incompetência escolar. O que nos parece estar em quase todas as histórias é um sofrimento decorrente das situações de humilhação e exclusão que esses adolescentes vivenciaram e/ou vivenciam no contexto escolar. Como analisa Souza (2007), as defasagens e dificuldades pedagógicas são, em muitas situações, expostas e ridicularizadas por colegas e até por professores.

Tal contexto leva-nos a refletir sobre a necessidade de o psicólogo ter atenção e sensibilidade para escolher o momento e a maneira de abordar assuntos relativos à escolarização do adolescente.

Tomemos como exemplo o caso de Marcos (nome fictício), de 14 anos, aluno do $6^{\circ}$ ano do Ensino Fundamental de uma escola pública paulistana. Foi levado por seus pais ao atendimento devido à queixa de desatenção, dificuldade de aprendizado e atraso no desenvolvimento psicomotor. $\mathrm{O}$ relato da escola enfocava sua dificuldade em ler e escrever e ritmo lento de aprendizado. A fala de sua mãe explicitava que Marcos não sabia ler nem escrever e voltava da escola chorando por não conseguir desempenhar as atividades propostas.

Durante os atendimentos, Marcos respondia muito brevemente às perguntas relativas ao contexto escolar. Durante a maior parte do processo de OQE, evitou envolver-se em atividades relacionadas à escrita. Seu incômodo nessas situações era evidente. Tal contexto levou-nos a não ter clareza sobre a real apropriação que Marcos tinha da linguagem escrita. Diante de tal percepção, preferimos não sugerir diretamente assuntos ou atividades relacionadas a conteúdos escolares. Sempre deixávamos disponíveis materiais que apresentavam conteúdos escritos, mas esperávamos pela manifestação do desejo de Marcos para trabalharmos essa questão.

Apenas a partir do décimo encontro o adolescente aceitou ler algumas palavras com sílabas simples, tarefa que desempenhou com dificuldade, mas com êxito. Procuramos entender o sofrimento que Marcos demonstrava ao relacionar-se com questões escolares e esperamos o momento em que ele se sentisse à vontade para adentrar esse campo.

É importante destacar nossa busca ativa junto à escola por meios que favorecessem o processo de escolarização de Marcos, rompendo aquela situação. A relação entre a escola e o adolescente havia produzido uma situação de paralisia. Desde anos o ambiente escolar sistematicamente propunha à sua classe tarefas que ele não tinha condições pedagógicas de cumprir, como, por exemplo, responder por escrito a perguntas que exigiam leitura e interpretação de textos. Por não conseguir executar as atividades propostas, ele se havia transformado em um aluno copista, como uma maneira de disfarçar o fato de não saber ler ou escrever, evitando algumas humilhações - aliás, uma estratégia bastante comum em tempos de "Progressão Continuada". Somado ao fato de ser comportado e agradável, isso o fazia passar despercebido pela maioria dos professores. Marcos, como muitos, preferia o sofrimento de ser invisível ao de ser visto pela incompetência.

\section{O lugar da fala e de outras linguagens no atendimento a adolescentes}

As atividades desenvolvidas durante os atendimentos em OQE a crianças com dificuldades em seu processo de escolarização não se constituem como foco da intervenção. Elas propiciam a emergência, problematização e elaboração de conteúdos relevantes para as questões educacionais e outras que as crianças necessitem comunicar, oferecendo-lhes oportunidade de usar diferentes linguagens. Assim, sempre levando em conta as características e necessidades de cada criança (ou grupo de crianças), podemos oferecer materiais gráficos, jogos, brinquedos, livros, gibis, instrumentos musicais e outros objetos e atividades. Os conteúdos mais constantes têm sido a história escolar da criança, os sentidos por ela construídos a respeito de seu processo de escolarização, sua relação com o aprender e desenvolver-se e sua apropriação dos conhecimentos escolares, principalmente a leitura e a escrita.

Tais instrumentos também podem ser oferecidos no trabalho junto a adolescentes, mas é importante uma adequação das atividades aos interesses de cada jovem e à sua faixa etária. Houve casos em que os adolescentes optaram pelo uso de jogos e materiais gráficos, mas o que ocorre com maior frequência são os atendimentos baseados no uso da fala como meio de comunicação, predominância relativamente comum nessa fase de desenvolvimento psicossocial.

Isso reafirma a necessidade de se dar espaço durante os atendimentos para as mais diversas formas de 
expressão, construindo com cada adolescente a maneira como seus atendimentos transcorrem.

Com relação a atividades e materiais que propiciem a explicitação de seu domínio e relação com os conteúdos escolares no contexto do atendimento, é preciso cuidar para que não reproduzam o que costuma ocorrer no ambiente escolar, de modo a não intensificar o estigma de incompetência, mas a rompê-lo. Assim, disponibilizamos materiais que não exijam um conhecimento muito além ou aquém do já apropriado pelo adolescente. Além disso, uma vez que atividades tipicamente escolares podem ser fonte de sofrimento para o adolescente, geralmente oferecemos ou criamos com o jovem atividades em que, por exemplo, a escrita e/ou a leitura possam surgir de modo significativo no contexto do que acontece no atendimento, mas de forma não escolar. Desse modo, surgem as anotações de resultados de jogos em que ambos se envolveram, a leitura de um relatório da escola sobre o jovem e outras atividades.

\section{Autoria do adolescente no processo de atendimento}

Durante os atendimentos, é importante que o adolescente possa apropriar-se de sua história escolar e refletir sobre o processo de produção de queixas acerca de sua escolarização.

O desvelar de questões e momentos que contribuíram para a produção da queixa escolar e culminaram no encaminhamento do adolescente para o atendimento é de fundamental importância para que se possam pôr em pauta os fatores políticos, institucionais, relacionais e pedagógicos que contribuíram para a construção das dificuldades que o adolescente enfrenta na escola, ampliando a compreensão da queixa e seus sentidos. Assim, a individualização da responsabilidade pelas dificuldades que enfrenta, a qual costuma ser operada pelo ambiente escolar, pode ser repensada e a culpabilização do estudante pode ser revertida. Os adolescentes, assim como as crianças e adultos, costumam trazer consigo imenso sentimento de culpa e desvalia, devido à responsabilização que introjetam (embora muitas vezes a ocultem) em relação à sua história de insucesso escolar.

Uma decorrência clara da busca pela autoria do adolescente no processo interventivo é a valorização de sua autonomia e postura ativa em relação aos atendimentos e aos possíveis caminhos deles decorrentes.

Um exemplo da importância de se legitimar a autonomia do adolescente aconteceu em um de nossos atendimentos, com uma garota de treze anos em cujo processo de escolarização a epilepsia havia gerado significativos efeitos, entre eles uma grande defasagem de aprendizagem e um relacionamento delicado com os colegas.

No quinto encontro, em que nosso trabalho previa um relatório de perguntas a ser encaminhado para a escola e encontros com seus professores, a reação de Lara (nome fictício) foi marcante. A garota calou-se, ficou bastante incomodada e recusou-se a conversar durante o atendimento. É importante destacar que já havíamos conversado antes sobre incluir a escola no processo interventivo; porém, neste momento, tal assunto despertou a preocupação de Lara e ela recusou-se a conversar sobre ele.

Quando já estávamos em outra atividade, ela conseguiu verbalizar seu incômodo: "Acho que meus colegas vão achar estranho você na minha escola". A aflição de Lara é compreensível e, diante de tal situação, foi maior a nossa preocupação em buscar incluí-la cada vez mais nas decisões referentes a seus atendimentos. Combinamos então que decidiríamos juntas quanto à ida ou não à escola, o que poderia ser ou não dito na escola e os possíveis professores a serem contatados, inclusive escrevemos conjuntamente a carta enviada à professora.

Entendemos que em todos os processos interventivos a autoria do cliente/instituição é de grande relevância, mas nos atendimentos a adolescentes com queixas escolares essa questão é de especial impacto, pois neles se trata de histórias nas quais os adolescentes são, na maioria das vezes, expropriados de sua capacidade de pensar, refletir e analisar por um tempo mais longo do que as crianças, tornando seus sentimentos de culpa e desvalia mais interiorizados e cristalizados. É de suma importância que o psicólogo os perceba em sua aptidão de apropriar-se do processo de atendimento e das decisões sobre os caminhos que podem favorecer sua escolarização e seu desenvolvimento como um ser integral.

Os manejos aqui discutidos tendem a propiciar que os adolescentes se reapropriem de sua capacidade de aprender, pensar e ser sujeito, restabelecendo-se a esperança tantas vezes perdida de um futuro digno, criativo e pleno de sentidos.

\section{Projeto de vida}

Percebemos, em nossa experiência com atendimento a adolescentes, que pensar e investir na escolarização costuma ganhar sentido (ou não) quando no bojo de um projeto de futuro. Assim, compreender o que esses jovens valorizam, o que buscam, quais são seus sonhos, anseios e planos de vida torna-se especialmente importante, e sobre esse terreno pode apoiar-se um processo de reflexão sobre sentidos de seguir (ou não) em seu processo de escolarização.

Liebesny e Ozella (2002) apontam que em diversas pesquisas sobre o projeto de vida de jovens, a escola aparece como percurso necessário e natural para entrada no mundo do trabalho, ou seja, para a inserção profissional e social, que representa o ritual de passagem da vida adolescente para o mundo do trabalho.

Segundo esses autores, as possibilidades de construções internas, subjetivas, dão-se a partir das atividades externas, nas relações sociais; por isso, ao investigarmos o projeto de vida de um jovem, devemos estar atentos para as condições em que esse projeto é construído. Lançamos uma pergunta que nos parece fundante: que condições estão sendo dadas para que o jovem construa qualquer projeto de vida diferente daquele no qual vive e sobrevive? 
Em se tratando de nosso atendimento em Orientação à Queixa Escolar com adolescentes, referirmo-nos a adolescentes que frequentemente não aprendem e sofrem exclusão dentro do sistema escolar.Procuramos entender de que maneira o insucesso escolar passa a constituir esses jovens e problematizar a individualização e culpa que assumem por processos institucionais e sociais doentios. Assim, buscamos uma inflexão esperançosa em tal constituição, imprimindo movimento onde há paralisia e adoecimento.

Entendemos que nosso atendimento em OQE deve propiciar o encaminhamento de um projeto de vida possível, desvelando as múltiplas determinações que impelem o adolescente à formulação de determinado projeto.

$\mathrm{Na}$ adolescência, os jovens são cobrados a fazerem escolhas importantes, especialmente a escolha profissional. Uma pesquisa Bock e Liebesny (2003) revelou estarem fortemente presentes, em projetos de vida de adolescentes de escolas paulistanas, o estudo, o trabalho e a família - sendo o trabalho o elemento central; porém o trabalho que aparece nos projetos de vida pesquisados refere-se exclusivamente à sobrevivência, resultando em ganho financeiro para compra e usufruto de bens. Não aparecem elementos críticos em relação ao trabalho que lhe confiram um caráter de contribuição social, envolvendo a transformação da realidade.

Concordando com as autoras, também temos encontrado jovens cujos sonhos de vida futura não vão muito além da mera sobrevivência e acesso a bens de consumo; ou seja, parece que estamos diante de um processo massivo de abortamento de anseios, ideais e esperanças.

Tendo em vista que a escola ainda aparece no imaginário social como garantia de inserção profissional e o trabalho como satisfação pessoal, temos clareza de que essas tendências precisam ser consideradas pelos psicólogos escolares quando atendem adolescentes com dificuldades em seu processo de escolarização. Trabalhamos para que os adolescentes atribuam novos sentidos a estas dificuldades e tenham condições de criar um projeto de vida possível, inclusive profissional, de modo crítico e consciente do seu papel no mundo.

Todos os adolescentes que atendemos até agora decidiram permanecer na escola e buscar maneiras de conquistar uma escolaridade mais bem-sucedida do que a que vinham tendo anteriormente. Participar da construção desta decisão tem sido, para nós, uma fonte permanente de tensão, dada a consciência que temos dos processos de homogeneização conservadora que geralmente predominam no ambiente escolar. Por outro lado, temos também a clareza de que grande parte dos adolescentes que estão fora da escola encontra-se em situação de risco e vulnerabilidade social. Dessa forma, caminhamos no fio da navalha. Necessitamos de uma atenção e autocrítica permanente de nossos trabalhos, para que estes não sejam meramente adaptativos. Transformar tal preocupação em gesto tem significado autorizar e fortalecer o adolescente de forma a pensar criticamente sobre a escola, percebendo o complexo jogo de forças que a habita e aproveitando o que ela tem de saudável para oferecer - e sempre o tem.

Acreditamos, ainda, ser fundamental valorizar os anseios, planos e projetos dos adolescentes, os quais são muitas vezes considerados pela sociedade como fruto de imaturidade e consequente falta de senso de realidade e pragmatismo.

\section{Algumas especificidades da intervenção na escola}

Em OQE, a não ser em situações muito raras, fazemos uma interlocução com a escola, que geralmente consiste de um pequeno questionário e de uma visita/reunião com educadores no local.

O pequeno questionário é enviado apenas após conquistar uma relação de confiança com o adolescente e mediante sua autorização. Exige um manejo cuidadoso, pois é comum esse envio suscitar insegurança e vergonha, pela expectativa de que venham respostas que o desenham como incapaz e mau. É preciso que nossa relação seja reassegurada e que o questionário adquira um significado de instrumento de ajuda e superação. A resposta a ele é também inserida em nossos encontros com ele, de maneira mediada por nós, buscando a potencialização das relações. Este processo todo, se bem conduzido, prepara a visita escolar, é de grande riqueza e costuma contribuir significativamente para que os trabalhos em OQE atinjam seus objetivos.

O uso e o manejo do questionário não se restringem aos adolescentes, mas costumam estender-se a todos os atendidos, independentemente da faixa etária e do ano escolar. No caso de adolescentes, há uma especificidade: eles têm muitos professores, diferentemente dos menores. Para quem enviar o questionário?

Coerentemente com nosso propósito de fortalecer a condição de sujeito dos participantes do processo, estudamos e decidimos isso com o próprio adolescente e com seus responsáveis, elegendo os caminhos mais potentes para a consecução dos objetivos. Isto favorece as relações com os educadores.

Esta eleição também ocorre quando vamos contatar a escola para solicitar uma reunião. Em geral, escolhemos um professor com quem o adolescente tem uma relação de potência e aposta, um com quem haja impasses, paralisia e/ou conflitos e alguém da equipe gestora - a coordenadora pedagógica ou a diretora. É importante procurar garantir a presença de pessoas da escola que possam sustentar cotidianamente os movimentos de desenvolvimento e superação no ambiente escolar, para que a conquista da autonomia da rede de relações produtora da queixa aconteça. Apesar disso, frequentemente a reunião com a escola não acontece com a composição planejada.

Como no caso do questionário, mediamos e potencializamos as relações com a escola. Assim, este encontro é inserido nos trabalhos com o jovem e sua família. 


\section{Considerações finais}

Procuramos discutir as especificidades do atendimento de adolescentes com queixas escolares, com o propósito de inspirar formas de intervir de outros psicólogos.

Iniciando pela explicitação de nossa concepção de adolescência, discorremos sobre características relevantes do cenário escolar dos jovens em dificuldades na escola que vêm constituindo a demanda em OQE, a serem consideradas em seu atendimento. A seguir, levantamos eixos e características de nossos trabalhos que vimos construindo na busca de contemplar as particularidades desta clientela.

Estamos vivenciando um momento no qual a Psicologia Escolar e Educacional busca construir e consolidar teorias e práticas profissionais mais condizentes com as necessidades contemporâneas, em uma perspectiva transformadora. Para tal, entendemos que partilhar conceitos e intervenções que construímos pode ser útil para identificarmos coletivamente em que aspectos é preciso avançar.

Acreditamos que, para consolidar formas de atendimento que possam realmente se colocar a serviço do fortalecimento do adolescente e da superação das dificuldades na escolarização, é necessário que o psicólogo atue com criticidade, criatividade e sensibilidade. É necessária uma busca constante de adequação de ferramentas teórico-metodológicas a essa demanda, não importando onde esse profissional esteja inserido, se na Educação, na Saúde, na Assistência Social ou em outro campo qualquer em que seja convocado a pensar e atuar diante de questões escolares.

\section{Referências}

Aguiar, W. M. J., Bock, A. M. B., \& Ozella, S. (2002). A Orientação profissional com adolescentes: um exemplo de prática na abordagem sócio-histórica. Em A. M. B. Bock, M. da G. M. Gonçalves \& O. Furtado (Orgs.), Psicologia Sócio-histórica - uma perspectiva crítica em Psicologia (pp. 163-178). São Paulo: Cortez.

Barros, M. N. S. (2002). Saúde sexual e reprodutiva. Em M. L. J. Contini (Coord.) \& S. H. Koller (Org.), Adolescência e psicologia: concepções, práticas e reflexões críticas (pp. 46-55). Rio de Janeiro: CFP.

Bock, A. M. B. (2004). A perspectiva sócio-histórica de Leontiev e a crítica à naturalização da formação do ser humano: a adolescência em questão. Caderno Cedes, 24(62), 26-43.
Bock, A. M. B., \& Liebesny, B. (2003). Quem eu quero ser quando crescer: um estudo sobre o projeto de vida de jovens de São Paulo. Em S. Ozella (Org.), Adolescências construídas: a visão da psicologia sócio-histórica (pp.203-222). São Paulo: Cortez.

Freller, C. C. (2001). Histórias de indisciplina escolar: um trabalho de um psicólogo numa perspectiva Winnicottiana. São Paulo: Casa do Psicólogo.

Leite, S. A. da S. (1993). A passagem para a $5^{\mathrm{a}}$ série: um projeto de intervenção. Cadernos de Pesquisa, 84, 31-42.

Liebesny, B., \& Ozella, S. (2002). Projeto de vida na promoção de saúde. Em M. L. J. Contini (Coord.) \& S. H. Koller (Org.), Adolescência e psicologia: concepções, práticas e reflexões críticas (pp. 62-67). Rio de Janeiro: CFP.

Mendes, A. S., Kuroda, M. S., \& Facci, M. G. D. (2008). A 'difícil' transição da quarta para a quinta série: alguns apontamentos a partir da Psicologia Histórico-Cultural. Máthesis, 9(1), 43-60.

Ozella, S. (2002). Adolescência: uma perspectiva crítica. Em M. L. J. Contini, (Coord.) \& S. H. Koller (Org.), Adolescência e psicologia: concepções, práticas e reflexões críticas (pp. 16-24). Rio de Janeiro: Conselho Federal de Psicologia.

Patto, M. H. S. (2008). A produção do fracasso escolar: histórias de submissão e rebeldia. São Paulo: Casa do Psicólogo.

Ruotti, C., Alves, R., \& Cubas, V. O. (Orgs). (2006). Violência na Escola: um guia para pais e professores. São Paulo: Imprensa Oficial do Estado de São Paulo e Associação Nacional de Direitos Humanos - ANDHEP.

Souza, B. P. (2007). Funcionamentos escolares e a produção de fracasso escolar e sofrimento. Em B. P. Souza, (Org.), Orientação à queixa escolar (pp. 241-278). São Paulo: Casa do Psicólogo.

Viégas, L. S. (2007). Dificuldades de escolarização e progressão continuada: uma relação complexa. Em B. P. Souza (Org.), Orientação à queixa escolar (pp. 307-328). São Paulo: Casa do Psicólogo. 


\section{Sobre as autoras}

Cárita Portilho de Lima (carita.portilho@yahoo.com.br)

Psicóloga pela Universidade Federal de Uberlândia-MG, mestre em Psicologia Escolar pelo Instituto de Psicologia da Universidade de São Paulo -IPUSP e psicóloga escolar da prefeitura municipal de Taboão da Serra.

Marina Borges e Silva Prado (marinabs_psico@hotmail.com)

Psicóloga pela Universidade Federal de Uberlândia-MG e mestre em Educação: Psicologia da Educação pela Pontifícia Universidade Católica de São Paulo.

\section{Beatriz de Paula Souza}

Mestre em Psicologia Escolar pelo Instituto de Psicologia da Universidade de São Paulo-IPUSP, psicóloga do Laboratório Interinstitucional de Estudos e Pesquisas em Psicologia 
